\title{
Smartphone + Teaching: Delivery of an Undergraduate Surveying Course Using Rain Classroom
}

\author{
Weifang Yang ${ }^{1,2,3} \&$ Haowen Yan $^{1,2,3, *}$ \\ ${ }^{1}$ Faculty of Geomatics, Lanzhou Jiaotong University, Lanzhou 730070, China \\ ${ }^{2}$ Natioanl-Local Joint Engineering Research Center of Technologies and Applications for \\ National Geographic State Monitoring, Lanzhou 730070, China \\ ${ }^{3}$ Gansu Provincial Engineering Laboratory for National Geographic State Monitoring, \\ Lanzhou 730070, China \\ *Corresponding author: Faculty of Geomatics, Lanzhou Jiaotong University, Lanzhou \\ 730070, China. Tel: 86-931-495-7211.E-mail: yanhw@mail.1zjtu.cn
}

Received: October 10, 2020 Accepted: December 11, 2020 Published: December 20, 2020

doi:10.5296/ije.v12i4.18252ＵRL: https://doi.org/10.5296/ije.v12i4.18252

\begin{abstract}
Traditional teaching methods using a blackboard, PowerPoint presentations and resources available through the Internet still play a leading role in university education. The popularity of smartphones and the use of We-Media and other information communication technologies have introduced the possibility of new teaching methods. This new technology combined with a constant endeavor at institutions of higher education to find more efficient teaching and learning tools brings us to a new teaching mode named "smartphone+". This represents an integration of traditional teaching tools and smartphones and can be realized using currently-available smartphone-based APPs. A practical application of the smartphone+ teaching mode has been implemented using the Rain Classroom APP in a surveying course for undergraduates majoring in Geomatics at Lanzhou Jiaotong University. The experiment has shown that the Rain Classroom-based smartphone+ teaching mode is an efficient method of conveying subject matter and is a valuable supplement to traditional teaching modes. It has a number of advantages over traditional teaching methods including online quizzes and tests, real time assessments, fast interaction, before-class preview and after-class online assessments.
\end{abstract}

Keywords: teaching mode, We-Media, smartphone+ teaching mode, online assessment 


\section{Introduction}

Surveying is a mandatory course for undergraduates majoring in Geomatics. In some universities in China, it is also a required course for the undergraduates majoring in transportation engineering, environment engineering, hydrology engineering and civil engineering (Guo, Bai, Cheng et al., 2020). Indeed, millions of undergraduates need to learn surveying in universities. Therefore, the delivery of a surveying course to undergraduates is of great importance. University instructors in surveying have never stopped exploring new teaching methods that can efficiently deliver knowledge and techniques to their students, and a number of achievements have been made.

Past surveying course teaching methods can be divided into three categories: (1) Teaching with a blackboard was among the earliest teaching methods and was commonly employed in universities 40 years ago. (2) In the early 1990s, computers became popular, and professors began to use the Microsoft's PowerPoint (PPT) to organize their teaching materials and deliver courses using the slides. During this stage, blackboards were still used; thus, this kind of teaching method is called "blackboard + slide" mode. (3) Starting from the middle of the 1990s, the Internet became integrated in classroom instruction at universities (Geng, 2020). During this period, PowerPoint slides and blackboards were still used in teaching leading to course delivery at this stage being called the "blackboard + slides + the Internet" mode ( $\mathrm{Li}$, Bai, 2020; Xie, 2020).

These teaching modes have been widely and successfully used in universities for years, and they basically work well (Chen 2019; Shu, Fan \& Zhu 2019). However, shortcomings of these modes became apparent as smartphones became the primary information communication technology and the common use of We-Media.

There are a number of limitations to the previous teaching methods. Firstly, the instructor and the students cannot interact efficiently in the classroom. Interactive communication is usually limited to the instructor and just a few vocal students. It is difficult for the instructor to interact with all of the students in the class, especially those that are timid.

Secondly, if only the traditional teaching modes are used, it is not easy for the instructor to quickly know some basic information of regarding a teaching activity. For example, the instructor would not know the number of the students who have previewed the materials given before class, the number of the students that are adapting to the course delivery speed and the number of the students who have not grasped particular concepts.

It has been observed that university students and instructors are no longer satisfied with the traditional teaching methods (Gideon, Folake, 2020). Students want to interact and communicate with their instructors outside of the classroom and know if they can adequately grasp the material. Instructors also want to know if their students understand the material. Fortunately, information communication technology has made it possible to overcome these limitations, especially when mobile phones become a popular communication tool in universities.

In this sense, a new teaching mode is necessary. On one hand, it should satisfy both 
instructors' and students' requirements for quick interaction in and outside the class. On the other hand, it needs to inherit the advantages of the traditional teaching modes. In other words, this new teaching mode should be an integration of blackboard, slides, the Internet with smartphone technology. This is referred to here as the "smartphone+" mode of teaching.

The remainder of this paper will provide a thorough discussion on how the "smartphone+" mode has been practiced in teaching surveying to undergraduates majoring in Geomatics in a university in China. Section two includes a brief scan of the software platform used. Section three examines how the new teaching mode is implemented for the teaching of a surveying course.

\section{Platforms Used in the Smartphone+ Teaching Mode}

The smartphone+ teaching mode was practiced by professors and lecturers at Lanzhou Jiaotong University from 2017 to 2019 when they delivered a surveying course to undergraduates majoring in Geomatics. Smartphone delivery was implemented using a software called "Rain Classroom," an APP developed for mobile phones and personal computers. The Rain Classroom is not stand-alone software. It relies on an APP called "WeChat" (see Figure 1). Rain Classroom may be viewed as an APP embedded inside WeChat, and it uses almost all the functions of WeChat. Thus, this section will introduce WeChat before a discussion of Rain Classroom.

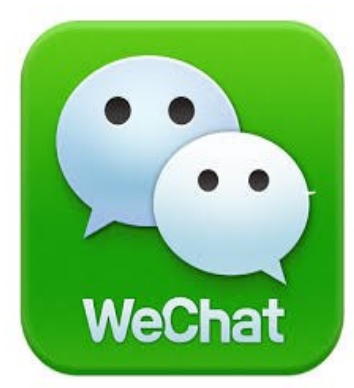

Figure 1. WeChat (https://guanjia.qq.com/ab/weixin/index.html)

\subsection{WeChat}

WeChat was released in 2011 by the Tencent company. At first, WeChat had only some simple functions like an ordinary messenger APP that was primarily used in China. After a few years, it has become a multi-purpose messenger, social media and mobile payment APP. Its users include the majority of Chinese citizens, and it has become the main mode of communication and interaction. Based on the 2019 WeChat Data insights and statistics, its monthly active user number is more than 1.15 billion. More than $99 \%$ of university students in China use WeChat. This is not only because of the WeChat's friendly multi-functions but also because of its affordable data charge. This has made it possible for the WeChat to be used in China's universities as a teaching platform to help professors to deliver courses. 
Flipped Class: Package MOOCs, videos, exercises and their voice into a PPT and push it to students' smartphones via WeChat.

Realtime Assessment: Tests can be posted anytime according to the teaching needs, and feedback can be got quickly.

Class Interaction: Bullet screen, submission, red envelope and random roll call motivate students to speak.

Online Assignments and Quizzes: Objective and subjective questions, attachment reply,

Figure 2. Five Commonly Used Functions of the Rain Classroom

\subsection{Rain Classroom}

Rain Classroom, launched in 2016, is a smart and free teaching tool jointly developed by the Xuetang Online and the Online Education Office of Tsinghua University (Tang, 2020). It is embedded in WeChat and used for teaching and learning in middle schools, colleges and universities. As a toolbox for teaching, Rain Classroom can provide enough teaching tools for instructors to assist them in the process of classroom teaching (Figure 2). The platform is student-centered and can accumulate the teaching, learning knowledge and experiences through the Internet. The purpose is to break the time and space constraints of interaction between instructors and students, and provide data-based information support for the teaching process. It is based on the following concepts:

\section{- Flipped Classroom}

This means the students, not the instructor, are at the center in the process of teaching and learning. Rain Classroom provides this function to the instructor to guarantee he/she can conveniently push all teaching materials such as the teaching slides, syllabus, quizzes, voice and video files to the students via the APP. Each student may easily get these materials on his/her Rain Classroom at any time and complete the tasks given by the instructor (e.g., preview before class, take quizzes, review after class).

- Real-time Assessment

Using this function, the instructor may send a question to the students in the class and get feedbacks from the students instantly. This can help the instructor know to what extent the students have grasped a knowledge point (e.g., a concept, a formula or a technique).

\section{- Class Interaction}

The APP provides functions such as "bullet screen" that allows each student to post his/her opinions, suggestions and questions at any time when Rain Classroom is active. If the instructor finds a topic among the posts that needs a respond, he/she may instantly discuss this with the students and solve the problem. In this way, the course delivery and learning process can be more efficient and the student can be more active than with traditional teaching modes. 
- Online Assignments and Quizzes

The instructor can send assignments, tests and quizzes to the students by this function, and the students can complete these tasks online, in or after the class, according to the deadline given by the instructor. The instructor may mark students' submissions online and each student can check his/her scores or/and answers given by the instructor.

- Data Reports

This function provides the instructor with fundamental data about this course. These data are very useful for the instructor to assess his/her own teaching effectiveness and every student's participation and performance. The data include the number of the students attending each lecture, the number of the students who have completed a specific assignment, average of a test/quiz/assignments, the number of the students who failed a quiz/test/exam, etc. With this data, the instructor can understand his/her teaching process in a quantitative way, thereby helping the instructor improve his/her teaching in a more informed manner.

These functions have made Rain Classroom a promising teaching tool in China's universities. The instructors who have used this APP have summarized its three advantages (Shu, Fan \& Zhu, 2019; Xie, 2020; Zhang 2019b):

Firstly, it is convenient to initiate a Rain Classroom class. After the instructor starts the PowerPoint in the computer, clicks on "Rain Classroom" on the top row of the PowerPoint (see Figure 3), and logs into WeChat, a rain classroom begins at the instructor's end (a smartphone and/or a personal computer) and a QR code appears on the screen. The instructor sends the QR code to the students' smartphones or projects it on the screen in the classroom to let them scan the code. After this step, both the instructor and the students have completed the sign-in process and enter the rain classroom. Only the instructor needs to download a Rain Classroom plugin for the computer. The students do not need to download any additional plugins.

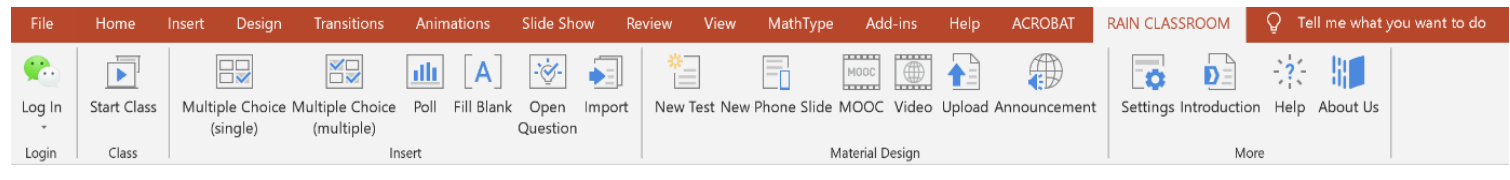

Figure 3. The Interface of the Rain Classroom in PowerPoint

Secondly, it is easy to learn and operate the APP. Because WeChat and PowerPoint are popular APPs among students and instructors in China's universities, it is very easy for them to learn the embedded Rain Classroom. The operations in Rain Classroom are just like that of WeChat, a program they use multiple times a day.

Thirdly, Rain Classroom provides a more convenient and easier communication and interaction for students and instructors than traditional teaching modes. For example, communications between the students and the instructor can be done at anytime and 
anywhere Wi-Fi works well. The instructor can upload his/her teaching materials (e.g., slides, assignments) via the Rain classroom and send them to students in or after class. The students can discuss with each other, get feedback from the instructor via the APP, and ask the instructor for answers to questions at any time. In addition, the instructor can determine if the teaching goals at a specific knowledge point have been achieved by getting quick feedback from student exercises, something that cannot be realized by the traditional teaching modes of teaching. This is especially useful for a course like surveying that contains complicated calculations. Using this Rain Classroom function, the instructor can quickly assess the number of students that have grasped a knowledge point, and determine if it is possible to move to the next knowledge point.

\section{Practical Application of Smartphone+: Rain Classroom for Undergraduates in Surveying}

Surveying is a mandatory and fundamental course for undergraduates majoring in Geomatics at Lanzhou Jiaotong University, China. The course emphasizes both theories and practical techniques in surveying. For theories, students are required to know basic concepts, fundamental principles and methods used in surveying, and the formulae used in surveying data processing. In practical techniques, students are required to know how to operate surveying instruments such as total stations and GPS, how to measure the length of a curve and the angle formed by two linesusing surveying instruments, how to survey and make topographic maps, and how to layout given points from maps to the surface of the Earth.

Although the traditional teaching modes have been used for decades, instructors and students felt they are not efficient and satisfactory in teaching and learning surveying after new communication tools such as smartphones became commonly used. According to a survey done by the authors, the students desire to have sufficient chances to participate in the whole teaching process in and out of the classroom, and be given sufficient time to discuss with their classmates and the instructor to know the basic information of the course (e.g., syllabus of the course, slides the instructor will use in next lecture, the score and answers in a test or quiz) as quickly as possible. On the other hand, the instructor also hopes to know sufficient information on students' progress.

The Rain Classroom-based smartphone+ mode may provide the ideal teaching and learning environment for meeting the needs of both students and instructors. This method of teaching has been put into practice in teaching surveying course to undergraduates in Geomatics at Lanzhou Jiaotong University. This new learning process with Rain Classroom is divided into three parts: the practices that occur before class, in class, and after class.

\subsection{Before Class}

Before the first class in surveying, the instructor sends the QR code generated by the APP to each student who has enrolled in the course. Each student then enters the Rain Classroom in his/her smartphone by scanning the QR code given by the instructor. After this step, the rain classroom is established. 


\section{Al Macrothink

The instructor can upload the teaching materials and push them to the students via the rain classroom at any time for the students to preview. These materials may be course syllabus, slides of the lectures, reading materials, videos, audios, assignments, tests, quizzes, news, announcements, questions and some links etc. The APP can also push the materials to a specific student at a specific time according to the instructor's instruction. The student can instantly get the notification from the Rain Classroom on his/her smartphone at almost the same time when the new message is pushed by the instructor.

When a student finishes a test, a quiz, an assignment, or a reading material, he/she can submit it to the rain classroom. After checking the rain class using the Rain Classroom APP (see Figure 4), the instructor can follow how the material is being processed by the students by the number of students that have finished doing a specific task, the average score of a quiz or other methods of assessment.

If a student has a question, he/she can post the question on the discussion board and discuss with classmates. He/she may also push the question quickly to the instructor via the APP and discusses with the instructor online.

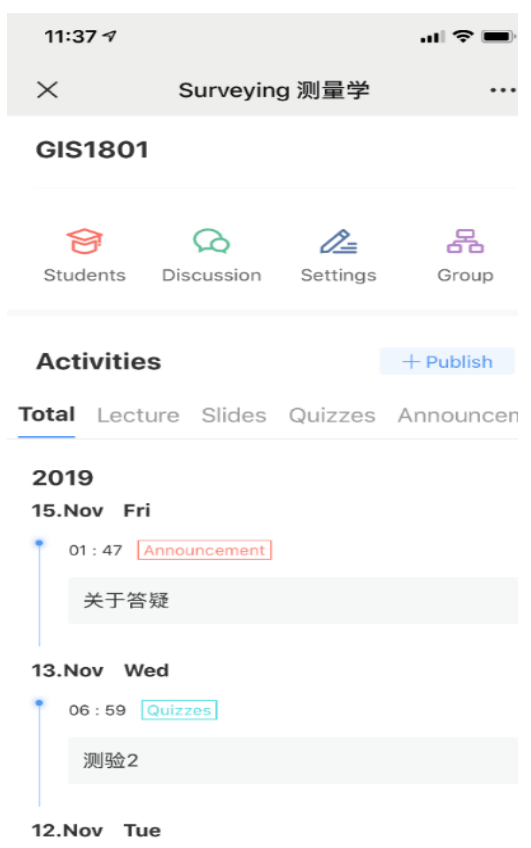

Figure 4. Interface of the Rain Classroom on the Smartphone

To increase the interest of students, questions can be pushed to the students before class by the instructor. For example, before the lecture of "traverse surveying", the following questions are pushed to the students:

- Why is traverse surveying necessary?

-What instruments are necessary in traverse surveying? 
- How does one obtain the coordinates of the traverse points in different types of traverse?

\subsection{In the Class}

When a rain class in surveying begins, each student is required to start his/her smartphone, login the Rain Classroom by scanning the QR code or entering his/her own username and password. The instructor starts the PowerPoint in his/her personal computer and login the Rain Classroom which embeds in the PowerPoint. After this step, the instructor can see a name list of the students attending the rain class. This is an automated form of a roll call.

In the process of course delivery, the traditional teaching tools/modes such as blackboards, slides and the Internet are still in use and play important roles. For example, in our rain class, the lectures are mainly presented by slides made and shown using PowerPoint, and the blackboard is also used occasionally for discussing questions temporarily raised by the students in class. Nevertheless, Rain Classroom, as a new element, plays a special role that cannot be substituted by other traditional teaching tools and modes.

- Quick comments and interactions

Using the Rain Classroom, the students may leave comments on any slides of the course before, in or after the class if they have any questions about any points of the slides. The comments can instantly appear on the screen on the instructor's side. If the instructor deems that one or more comments are worthy of a stop, he/she may stop the lecture and launch a short discussion with the students.

Here is such a typical example. A number of students asked a similar question "why a 60-based system is used in angle conversion?" on the discussion board when one of the instructors was lecturing on "Angle Surveying". After receiving the message, a discussion started with the students. The instructor felt it was important to answer this question before other formulae and techniques were introduced.

- Quick exercises and answers

As has been discussed in a previous section, surveying for undergraduates emphasizes both fundamental theories and practical techniques. Because some theories in surveying contain complicated graphics and/or formulae and some surveying techniques need to be implemented using various special tables, it is usually difficult to do exercises in class through traditional teaching modes. This has changed with Rain Classroom. In our rain classes, it is very common for the instructor to give the students some complicated exercises and ask them to submit their answers in given time via the APP. The following presents such an example. 


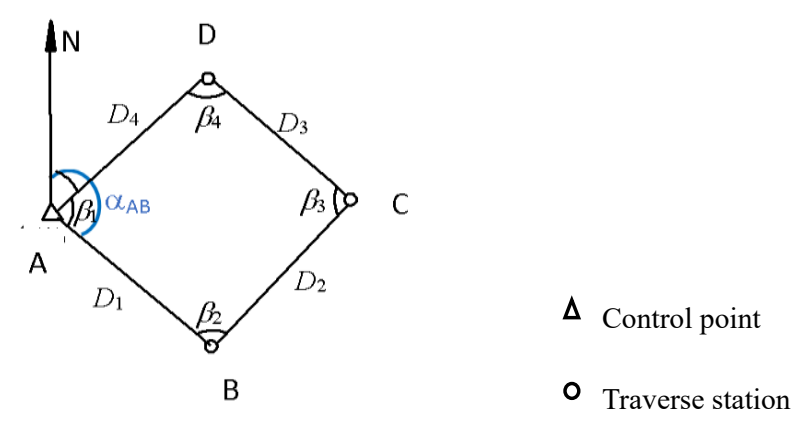

Figure 5. A Closed Traverse

The students are given a graphic of a traverse with surveyed distances and angles (see Figure 5), and the surveyed data listed in Table 1. The figure and the table are pushed to the students. They are required to submit their answers in 15 minutes by filling the blanks on the Rain Classroom APP.

After the students have completed submitting their answers via the APP, the Rain Classroom APP can quickly mark the questions within a second and send the score to each student together with the correct answers that are prepared in advance by the instructor. The instructor also can know the number of students who have completed the exercise correctly, which helps him/her determine how to approach the next step.

- In-class quizzes and real time marking

The Rain Classroom makes quizzes and tests much simpler to both the instructor and the students than that of the traditional teaching tools such as blackboards and slides. The instructor pushes a quiz to each student via the Rain Classroom and each student is notified instantly when they may start the quiz. After the quiz is completed, the answers are submitted via the APP. The instructor receives the submissions right away and may immediately mark the submissions and know the whole status of the quiz, such as the average score, the highest/lowest score, the number of the students who passed the quiz, and the students who answer a specific question correctly (Figure 6). The instructor can also convey this information to each student through the APP.

Indeed, in-class quizzes through Rain Classroom makes the surveying class simpler and more efficient than the traditional teaching modes. It helps both the instructor and the students understand their progress on knowledge points, and helps the instructor to make decisions on how to continue with the teaching process. 


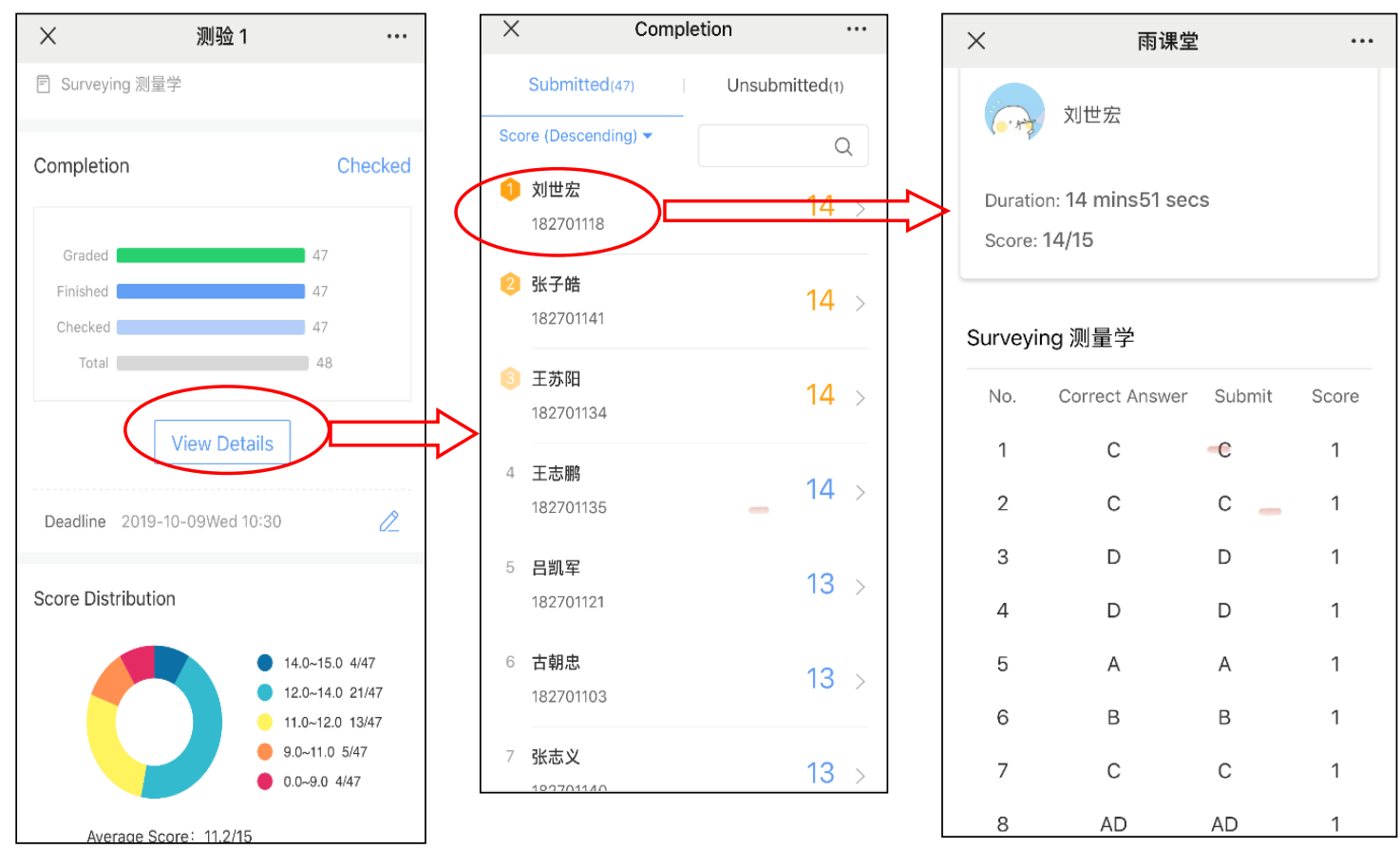

Figure 6. Statistical Data of a Quiz Shown on the Instructor's Smartphone

\subsection{After the Class}

With traditional teaching modes, it is difficult for the instructor to interact with the students, mark students' assignments, and test the students online. But these functions are necessary to the instructor and the students.

- Quick Interaction

If the instructor suddenly finds that he/she has made a mistake in an assignment that the students are doing, or a student encounters a problem or question that they cannot solve without the instructor's help, quick interactions between them becomes particularly important after class. The functions provided by the Rain Class improves after-class interactions.

- Realtime Assessment at Home

The instructor may assign some exercises to the students by the Rain Classroom APP for students to finish at home. Correctness of the answers of the exercises are automatically and instantly judged by the APP online. Sometimes, each student is allowed to practice specific exercises repetitively until he/she feels the answers are satisfactory.

- Online Quizzes and Tests

Online quizzes and tests are essential. If a student cannot attend a lecture, he/she may do the quiz or test at home just like he/she is in the classroom using the APP. 


\section{Conclusion}

Traditional teaching modes or tools, including blackboards, slides, and the Internet, have been common in university instruction. Modern technology brings about opportunities for change. Hence, this paper proposed a new teaching mode called smartphone + , and gives a practical example for the instruction of surveying.

The smartphone+ teaching mode has been implemented in surveying for the undergraduates majoring in Geomatics at Lanzhou Jiaotong University in China using an APP called "Rain Classroom". The practical application has shown that the Rain Classroom-based smartphone+ teaching mode is a valuable supplement to existing teaching modes. It has a number of advantages that the traditional teaching modes do not have in teaching surveying, including its online quizzes and tests, real-time assessments, quick interaction and communication outside the classroom.

Our explorations in the smartphone+ teaching mode and experience using Rain Classroom have shown that smartphone + is an efficient teaching mode. Our work is still at a preliminary stage. There is still much to learn to properly implement smartphone+ learning tools in a surveying course. The results clearly demonstrate that the integration of the smartphone+ teaching mode through Rain Classroom and other technologies is deserving of further investigation.

\section{Acknowledgments}

The work described in this paper is funded by the National Natural Science Foundation of China (No.40261076) and LZJTU EP 201806.

\section{References}

Chen, Y. Q. (2019). Application of blended teaching mode to college English class based on MOOC and "Rain Classroom". Professional Education, 8(3), 123-127. https://doi.org/10.12677/VE.2019.83021

Geng, X. (2020). Discussion on large-scale online education practice amid the novel coronavirus outbreak. International Journal of Education, 8(4), https://doi.org/10.5121/ije.2020.8402 13

Gideon, A. A., \& Folake, A. A. (2020). The suitability of selected social media for language education. International Journal of Education, 8(1). https://doi.org/10.5121/ije.2020.8104 55

Guo, N., Bai, Y. B., Cheng, X., et al. (2020). Design and implementation of electric power patrol monitoring system based on Beidou and mobile network. Journal of $\begin{array}{llll}\text { Geovisualization andysis, } & \text { 4(2), }\end{array}$ https://doi.org/10.1007/s41651-020-00069-0 
Li, X. M., \& Bai, F. T. (2020). Intelligent teaching practice of structural mechanics based on Rain Classroom. Innovative Education Research, 8(3), 350-355. https://doi.org/10.12677/CES.2020.83056

Shu, B., Fan, F., \& Zhu, X. (2019). Use of rain classroom as a teaching tool in a biochemistry course. Journal of Curriculum and Teaching, 8(3), 15-23. https://doi.org/10.5430/jct.v8n3p15

Tang G. M., (2020). Research on blended teaching design of mental health course in higher vocational college - take "stress management and frustration coping of college students" as an example. Progress in Education, 10(4), 521-526. https://doi.org/10.12677/AE.2020.104089

Xie J. (2020). The Practice and Application of Rain Classroom in the Teaching of Organic $\begin{array}{llll}\text { Chemistry. Progress in } & \text { Education, }\end{array}$ https://doi.org/10.12677/AE.2020.101010

\section{Copyright Disclaimer}

Copyright for this article is retained by the author(s), with first publication rights granted to the journal.

This is an open-access article distributed under the terms and conditions of the Creative Commons Attribution license (http://creativecommons.org/licenses/by/3.0/). 